\title{
A RESPONSABILIDADE CIVIL DO PRÁTICO: DOS DIPLOMAS LEGAIS À PRÁTICA DO PORTO DE NATAL
}

\author{
Jéssica Hellen da Silva XAVIER* e Brenda Camilli Alves FERNANDES \\ Instituto Federal de Educação, Ciência e Tecnologia do Rio Grande do Norte - IFRN \\ jessicaxaviier@gmail.com*
}

DOI: 10.15628/observatorio.2014.2909

\section{RESUMO}

A responsabilidade Civil do prático é um tema em ascensão, porém ainda pouco discutido pela legislação e doutrina brasileira. Este trabalho tem como objetivo analisar a responsabilidade civil do prático, levando como base as leis, normas, doutrina e jurisprudência, bem como entender as medidas adotadas pela Comunidade Marítima internacional com a finalidade de identificar possíveis soluções para as lacunas deixadas pela legislação pátria. Foram usados autores com os diferentes pontos de vista, para que se possa analisar e concluir a melhor maneira de dirimir o problema central. Antes de adentrar no assunto principal, foram explicadas noções de Responsabilidade Civil, Praticagem, Tribunal Marítimo e sobre o próprio prático. Dentro dos procedimentos metodológicos fizemos uma análise teórica com abordagem qualitativa baseada nas normas, leis e doutrina sobre a Responsabilidade Civil dos Práticos. Realizamos pesquisas de caráter descritivocomparativo por meios bibliográficos, sítios de internet e documental. Por fim, fizemos uso de uma entrevista semi-estruturada com o Presidente da Associação dos Práticos de Natal. Os resultados desta monografia confirmaram que a legislação brasileira precisa ter um posicionamento direto sobre a responsabilização civil dos práticos, mostrando um atraso frente à legislação de outros países. Observou-se a tendência dos processos que versam sobre este assunto ficarem apenas sob âmbito do Tribunal Marítimo, sendo escassa a quantidade deste tipo de processo na Justiça Comum Brasileira.

PALAVRAS-CHAVE: Responsabilidade Civil. Prático. Praticagem. Legislação brasileira.

\section{PILOT'S CIVIL LIABILITY: OF LEGISLATION TO PRACTICE OF THE PORT OF NATAL}

\begin{abstract}
Pilot's Civil liability is an issue rising, but with a few discussions by Brazilian law and doctrine. This paper aims to analyze the pilot's liability, taking as a basis the laws, rules, doctrine and jurisprudence as well as understand the measures adopted by the international maritime community in order to identify possible solutions to the gaps left by legislation homeland. Authors with different points of view were used, so we can analyze and conclude the best way to solve the central problem. Before entering the main subject, notions of Liability, Pilotage, Marine Court and the pilot itself were explained. Within the methodological procedures, we did a theoretical analysis with a qualitative approach based on the rules, laws and
\end{abstract}

doctrine on Pilot's Civil Liability. We research by comparative-descriptive character for bibliographic resources, internet sites and documentary. Finally, we used a semi-structured interview with the President of the Association of Practical Natal. The results of this thesis were confirmed that Brazilian legislation need to have a direct position on the civil liability of the practical, showing a delay forward the legislation of other countries. Observed the tendency of proceedings related to this matter remain just under the framework of the Maritime Court, becoming scarce amount of these types of proceedings in the Common Brazilian Justice.

KEYWORDS: Liability. Practical. Pilotage. Brazilian law. 


\section{INTRODUÇÃO}

O serviço de praticagem consiste em importante atividade para o comércio exterior, especialmente para o comércio marítimo, de interesse público e privado. É tido por muitos, inclusive, como indispensável para evitar acidentes, até mesmo ambientais, que costumam trazer grandes prejuízos financeiros e danos irreversíveis para toda a sociedade.

A responsabilidade civil do Prático nunca esteve em tamanha evidência, visto que, os processos administrativos versando sobre este tipo de responsabilidade, bem como o debate acerca da essencialidade do serviço de praticagem vêm aumentando cada vez mais e, com isso, a discussão sobre esse assunto. Outro fator que coloca em evidência o serviço de praticagem é a suposta grande remuneração recebida pelos práticos. Fato este noticiado pela imprensa do país nos últimos anos, especialmente em 2012 e 2013. Em 2013 o governo federal tomou algumas medidas buscando modernizar e diminuir as tarifas da praticagem no Brasil, tentando, inclusive, melhor regular a profissão dos práticos.

Frente a esse aspecto, surge a necessidade de se analisar a legislação brasileira no que diz respeito à responsabilidade civil do prático, questionar possíveis lacunas que podem ou não serem resolvidas pelos tribunais pátrios e sugerir soluções que possam amenizar os problemas relativos a este assunto, buscando, assim, até mesmo, se não a uniformização do entendimento, mas o seu aclaramento.

O presente trabalho pretende fazer uma análise teórica com abordagem qualitativa sobre a responsabilidade civil do prático, de modo a descobrir como a legislação trata do tema e fazer uma relação entre a legislação, a doutrina e a prática do Porto de Natal, analisando como este assunto vem sendo tratado na nossa cidade. Para isto, temos como base as Normas da Autoridade Marítima para o Serviço de Praticagem, a lei n. 9.537/97 (LESTA), as decisões do Tribunal Marítimo e a doutrina.

A pesquisa é de caráter descritivo-comparativo, no qual se desenvolverá análise bibliográfica, documental e sítios da internet. Antes de abordar o tema principal do trabalho, serão realizados estudos para buscar entender os principais envolvidos no assunto: a responsabilidade civil, a praticagem e o próprio prático.

Em seguida, será feita uma análise para avaliar as eventuais lacunas deixadas na legislação brasileira no que diz respeito à responsabilidade civil do prático e o que diz a doutrina sobre o assunto. Após este estudo, realizaremos uma comparação entre a nossa legislação e a de outras nações que já especificam os deveres do prático referentes a sua responsabilidade civil.

Para finalizar, poderemos observar a análise de resultados referente à praticagem no Porto de Natal, por meio de entrevista semi-estruturada realizada com prático e também presidente da Associação dos práticos de Natal, Sr. Sebastião Rodrigues.

Esta monografia está estruturada em cinco capítulos. O primeiro - Responsabilidade Civil - esclarece as noções básicas de responsabilidade civil para que o leitor, por mais que não conheça o que se trata o assunto, possa ter entendimento sobre o mesmo. 0 segundo Praticagem - estabelece a definição do serviço, bem como dos elementos necessários para a realização da mesma, inclusive, o objeto principal deste assunto, o prático. No terceiro capítulo - 
A responsabilidade Civil do Prático - faremos o link entre os dois capítulos anteriores com a análise da responsabilidade civil do prático de acordo com a doutrina e legislação brasileira.

Na quarta parte do estudo - A responsabilidade Civil no Direito Comparado - poderemos analisar a legislação de outros países que já se manifestaram claramente sobre o assunto. Por último, no capítulo quinto - Demonstraremos a partir da entrevista realizada na Associação dos Práticos de Natal, a realidade do assunto em prática no Porto da nossa cidade.

\section{RESPONSABILIDADE CIVIL}

A expressão "responsabilidade" possui muitos sentidos segundo a doutrina. De acordo com Stoco (2013, p. 154) responsabilidade tanto pode ser sinônimo de diligência e cuidado, no plano vulgar, como pode revelar a obrigação de todos pelos atos que praticam, no plano jurídico.

Imputar a responsabilidade a alguém, é considerar-Ihe responsável por alguma coisa, fazendo-o responder pelas consequências de uma conduta contrária ao dever, sendo responsável aquele indivíduo que podia e devia ter agido de outro modo (TOMASZEWKY, 2004 apud STOCO, 2013, p. 154).

"Este mesmo termo, pode levar também, a idéia de uma relação obrigacional, revela, então, um dever, um compromisso, uma sanção, uma imposição decorrente de algum ato ou fato" (Fiuza, 2006. p. 32 apud Stoco, 2013, p. 154)

Em 1916 o Código Civil era extremamente simples, composto por uma única cláusula de Responsabilidade Civil em seu artigo 159, onde a culpa era necessária para qualquer tipo de indenização e raros eram os casos de responsabilidade objetiva. "No sistema da lei revogada, a regra era a responsabilidade civil subjetiva, inexistindo previsão de dever de indenizar sem culpa" (Lopes, 2012, p. 2), mas qual seria a definição de "culpa"?

A “culpa" é outra expressão muito discutida pela doutrina. Segundo George Ripet (1979 apud STOCO, 2013, p. 182) afirma que não há definição legal de culpa; que é impossível mesmo tentar defini-la. Já Cavalieri (2012, p. 36) foi além e definiu culpa como "conduta voluntária contrária ao dever de cuidado imposto pelo Direito, com a produção de um evento danoso involuntário, porém previsto ou previsível". Mais uma definição foi dada por Stoco, que diz:

A culpa em sentido amplo, tanto pode ser a expressão da consciência e vontade dirigidas a um fim perseguido e querido, embora ilícito, como o descumprimento de um dever de cuidado ou de diligência em razão do açodamento, de desídia ou de imperfeição técnica, ainda que sem intenção de prejudicar. (STOCO, 2013, p. 183).

Com o desenvolvimento da sociedade, observou-se que esse sistema baseado na comprovação da culpa, não era suficiente para realizar decisões justas, pois é um processo oneroso e por diversas vezes até impossível.

A partir dessa linha de pensamento, a responsabilidade civil sem culpa foi se tornando mais comum no ordenamento jurídico. Esta passou por uma grande evolução ao longo do século XX. "Foi, sem dúvida, a área da ciência do direito que sofreu as maiores mudanças, maiores até que no direito de família" (Cavalieri, 2013). Ainda segundo Cavalieri (2013) a implantação da 
indústria, a expansão do maquinismo e a multiplicação dos acidentes deixaram exposta a insuficiência da culpa como fundamento único e exclusivo da responsabilidade civil. Neste novo contexto, o causador do dano só não terá dever de indenizar se conseguir provar alguma das causas de exclusão do nexo causal - caso fortuito, força maior, fato exclusivo da vítima ou de terceiros.

Para Lopes (2012, p. 3) foi em 1988, com a promulgação da Constituição Federal que aconteceu a revolução nessa matéria. Estabeleceu em seu artigo 37, § 6ㅇ, a responsabilidade civil objetiva do Estado, estendendo-a às pessoas jurídicas de direito privado prestadoras de serviço público.

Com efeito, dispõe o artigo 37, § 60, da Constituição Federal que as pessoas jurídicas de direito privado prestadoras de serviço público responderão, independentemente da ocorrência de culpa, pelos danos que seus agentes, nessa qualidade, causarem a terceiros. (LOPES, 2012, p. 3).

De acordo com as mudanças ocorridas na nossa Constituição, o significado de responsabilidade civil também teve suas modificações. De acordo com Cavalieri, responsabilidade civil é:

Um dever jurídico que surge para recompor o dano decorrente da violação de um dever jurídico originário... Daí ser possível dizer que toda conduta humana que, violando dever jurídico originário, causa prejuízo a outrem é fonte geradora de responsabilidade civil. (CAVALIERI, 2004, 24 p. apud PIMENTA, 2007, p. 10).

Outra definição é dada por Diniz citada por Stoco:

A aplicação de medidas que obrigue a alguém a reparar o dano moral ou patrimonial causado a terceiros em razão de ato do próprio imputado, de pessoa por quem ele responde, ou de fato ou coisa ou animal sob sua guarda (responsabilidade subjetiva), ou, ainda, de simples imposição legal (responsabilidade objetiva). (DINIZ, 2003, p. 74 apud STOCO, 2013. p. 155).

Então, podemos entender como responsabilidade civil o dever de reparar um dano causado a outrem, pela própria pessoa ou coisas/animais/fatos que estejam sob sua responsabilidade, podendo o ato ter sido intencional ou não.

\subsection{RESPONSABILIDADE CONTRATUAL E EXTRACONTRATUAL}

De acordo com conceito de responsabilidade civil, percebemos que o dano causado a outrem gera o dever de indenizar. Esta obrigação passível de violação pode ser decorrente de uma relação jurídica obrigacional preexistente, o dever gerado a partir de um contrato, ou pode ter como causa geradora um dever por norma geral do Direito, ou pela própria lei.

É com base nisso que a doutrina divide a responsabilidade civil em contratual ou extracontratual. "Se preexiste um vínculo obrigacional, e o dever de indenizar é consequência do inadimplemento, temos a responsabilidade contratual, também chamada de ilícito contratual ou relativo" (CAVALIERI, 2005, p. 38). Haverá a responsabilidade contratual quando a obrigação jurídica violada já está prevista em contrato. Ou seja, é a violação de uma obrigação anterior estabelecida pelos contratantes. "A responsabilidade contratual surge quando uma delas (ou 
ambas) descumpre esse dever, gerando o dever de indenizar" (CAVALIERI, 2012 apud STOCO, 2013, p. 192).

Porém, se a violação é pertinente a um dever jurídico imposto pela lei, se caracteriza pela responsabilidade civil extracontratual, podendo ser chamada também de ilícito aquiliano ou absoluto. Neste caso, não exige que haja um contato anterior pelo autor da ação danosa e a vítima. "Se esse dever surge em virtude de lesão a direito subjetivo, sem que entre o ofensor e a vítima preexista qualquer relação jurídica que o possibilite, temos a responsabilidade extracontratual" (CAVALIERI, 2005, p. 39). Para clarificar, podemos citar Stoco (2013, p. 192):

Em resumo, a responsabilidade extracontratual é o encargo imputado pelo ordenamento jurídico ao autor do fato, ou daquele eleito pela lei como responsável pelo fato de terceiro, de compor o dano originado do ato ilícito, ou seja, da obrigação daquele que por ação ou omissão voluntária, violar direito e causar dano a outrem. (STOCO, 2013, p. 192).

Então, podemos observar que ambas acontecem quando há a violação de um dever jurídico já existente, o fator principal para a distinção está na fonte deste dever.

\title{
2.2 RESPONSABILIDADE OBJETIVA X RESPONSABILIDADE SUBJETIVA
}

Segundo alguns doutrinadores, a exemplo Cavalieri, a responsabilidade civil objetiva e subjetiva não são duas formas distintas de responsabilidade civil, mas sim formas diferentes de considerar a obrigação de reparar o dano. A responsabilidade civil subjetiva é a regra em nosso Código Civil. Podemos observar através do artigo 186, que prevê: "Aquele que, por ação ou omissão voluntária, negligência ou imprudência, violar direito e causar dano a outrem, ainda que exclusivamente moral, comete ato ilícito" (BRASIL, 2002).

Na responsabilidade subjetiva para obter a reparação a vítima tem que provar que o dano gerado foi culpa do agente. Obrigatoriamente é preciso provar a ocorrência do fato, o dano decorrente disto provando o nexo causal entre eles e que o réu agiu com culpa no sentido amplo, ou seja, negligência, imperícia ou impudência. A culpa é essencial para a responsabilidade civil subjetiva.

\begin{abstract}
A ideia de culpa está visceralmente ligada à responsabilidade, por isso que, de regra, ninguém pode merecer censura ou juízo de reprovação sem que tenha faltado com o dever de cautela em seu agir. Daí ser a culpa, de acordo com a teoria clássica, o principal pressuposto da responsabilidade civil subjetiva. (CAVALIERI, 2005, p. 39)
\end{abstract}

Já a responsabilidade objetiva se diferencia da subjetiva pelo fato de ser necessário apenas comprovar o fato, o dano e nexo causal. É considerada como cláusula geral de responsabilidade objetiva, o art. 927, parágrafo único, no Código Civil de 2002, que prevê: "Haverá obrigação de reparar o dano, independentemente de culpa, nos casos especificados em lei, ou quando a atividade normalmente desenvolvida pelo autor do dano implicar, por sua natureza, risco para os direitos de outrem" (BRASIL, 2002).

No caso desta responsabilidade é invertido o ônus da prova, ou seja, o réu é que terá que provar que não teve culpa no ocorrido, caso isso não aconteça, será responsabilizado do dano. 


\subsubsection{Imprudência, negligência e imperícia como atributos da culpa}

Para que se obtenha total entendimento do assunto, acredito que é necessário a clareza na definição de imprudência, negligência e imperícia. Segundo alguns dicionários da Língua Portuguesa, imprudência significa o ato de agir perigosamente, com falta de moderação ou precaução. "A imprudência é a falta de cautela, o ato impulsivo, o agir açodado ou precipitado, através de uma conduta comissiva" (STOCO, 2013, p. 184). Podemos exemplificar através do ato de ingerir bebidas alcoólicas e dirigir, ou mesmo, de um médico realizar uma cirurgia de risco sem os equipamentos necessários/adequados.

A negligência pode ser caracterizada pela falta de cuidado, desleixo, zelo. "Pode-se identificá-la na conduta do empregado que deixa de trancar a porta ou o cofre da empresa, que vem a ser assaltada" (STOCO, 2013, p. 185).

Podemos caracterizar a imperícia pela falta de capacidade técnica do profissional em sua área, ou seja, demonstrando incapacidade ao que se propõe. Pode-se identifica-la através da ação ou omissão.

Após a definição de Responsabilidade Civil e suas vertentes, nos aprofundaremos nos assuntos relativos ao serviço de praticagem.

\section{PRATICAGEM}

O serviço de praticagem está definido pela Lei n. 9.537/97 conhecida como LESTA - Lei de Segurança do Tráfego Aquaviário, - em seu art.12: "O serviço de praticagem consiste no conjunto de atividades profissionais de assessoria ao Comandante requeridas por força de peculiaridades locais que dificultem a livre e segura movimentação da embarcação" (BRASIL, 1997). Ou seja, o serviço de praticagem é disponível em áreas restritas, onde o acesso se torna mais delicado e perigoso. Ocorre nos portos onde a movimentação do navio é limitada, por difícil acesso aos canais marítimos e condições climáticas desfavoráveis.

Não foi possível determinar, exatamente, quando esse serviço teve seu início, porém, segundo alguns pesquisadores, é correto afirmar que a praticagem é tão antiga quanto o comércio marítimo. "Dela tem-se registro no Código de Hamurabi, nos famosos Rolos de Rhodes e Oleron e em algumas passagens bíblicas, já sendo largamente utilizada na antiguidade pelos Gregos e Fenícios" (PIMENTA, 2007, p. 57). No Brasil, o primeiro documento histórico que regulariza o serviço de praticagem é o Decreto de 12 de junho de 1808, assinado por D. João VI:

Porquanto pela Carta Régia de 28 de Janeiro proximo passado, fui servido permittir aos navios das Potencias alliadas e amigas da minha Côroa, a livre entrada nos Portos deste Continente; e sendo necessario, para que aquelles dos referidos navios que demandarem o Porto desta Capital não encontrem risco algum na sua entrada ou sahida, que haja Pilotos Praticos desta Barra, capazes e com os sufficientes conhecimentos, que possam merecer a confiança dos Commandantes ou Mestres das embarcações que entrarem ou sahirem deste Porto: hei por bem crear o logar de Piloto pratico da Barra deste Porto do Rio de Janeiro, e ordenar que sejam adimittidos a servir nesta qualidade os individuos que tiverem as circunstancias prescriptas no Regimento que baixa com este, assignado pelo Visconde de Anadia, do meu Conselho de Estado, Ministro e Secretario de Estado dos Negocios da Marinha e Dominios Ultramarinos, e que 
possam perceber pelo seu trabalho os emolumentos ahi declarados. O Infante D. Pedro Carlos, meu muito amado e prezado sobrinho, Almirante General da Marinha, o tenha assim entendido e o faça executar. Palacio do Rio de Janeiro em 12 de Junho de 1808. (BRASIL, 1808).

Ao passar dos anos surgiram outros decretos especificando as atividades da praticagem e suas áreas de atuação, porém, foi em 1940 que surgiu um novo regulamento para a Capitania dos Portos, incluindo toda regulamentação dos serviços de praticagem e criando as Corporações dos práticos. Ficou determinado que a administração dessas corporações fosse exercida por um Prático-Mor, um Prático Ajudante e um Tesoureiro, eleitos em reunião convocada e presidida pelo Capitão dos Portos, devendo seus atos serem sempre submetidos à aprovação do mesmo. Os Serviços de Praticagem ficaram classificados como organizações de utilidade pública, de interesse da Segurança Nacional e da alçada do Ministério da Marinha.

Em 1997 surgiu a Lei de Segurança do Tráfico Aquaviário - LESTA -, outro avanço na regulamentação do serviço. Possui um capítulo específico sobre a praticagem, classificando-o como essencial e permanentemente disponível, incumbindo a autoridade marítima a estabelecer o número de práticos necessários para cada zona de praticagem, bem como, fixar o preço do serviço em cada uma dessas zonas. Zona de praticagem, segundo a Norman 12, é a área geográfica demarcada por peculiaridades locais que dificultam a livre e segura movimentação das embarcações, exigindo a constituição e funcionamento ininterrupto dos serviços de praticagem para essa áera. Compete a Diretoria de Portos e Costas estabelecer as Zonas de Praticagem.

Essa definição de ZP é dada pela NORMAM 12 - Norma da Autoridade Marítima para o Serviço de Praticagem - que tem propósito estabelecer diretrizes para o serviço de praticagem em águas jurisdicionais brasileiras, assim como as citadas anteriormente. Essa norma foi criada no ano de 2000, sendo a mais recente nos dias atuais. Dentre o objetivo de ratificar definições e diretrizes faladas anteriormente, determina a competência do Diretoria de Portos e Costas (DPC) estabelecer as Zonas de Praticagem em que a utilização do serviço é obrigatória ou facultativa e especificar as embarcações dispensadas do serviço.

As praticagens são organizadas por Estado ou Região, a critério da Autoridade Marítima, em função de particularidades de cada local, considerando-se a frequência média de navios, a localização dos portos e terminais de outros aspectos pertinentes à segurança da navegação. (PIMENTA, 2007, p. 75)

Para a realização do serviço de praticagem são necessários: a atalaia, a lancha de praticagem e o próprio prático. A atalaia, segundo a NORMAM 12, é a estrutura operacional e administrativa organizada de formar a prover, coordenar, controlar e apoiar o atendimento do Prático à embarcação em uma Zona de Praticagem (ZP). Também é denominada de Estação de Praticagem. A atalaia é uma estrutura que tem como objetivo atender de maneira eficiente e ininterruptamente o serviço de praticagem. De acordo com o Conselho Nacional de Praticagem (CONAPRA) a atalaia também é composta pela estrutura operacional, instalações apropriadas para alojar os práticos de serviço, bem como, as tripulações das lanchas que estiverem de prontidão, além do controle dos navios que farão uso de seus serviços. Equipamentos meteorológicos, de comunicação e salvatagem também são encontrados na estrutura. Já a lancha de praticagem "é a embarcação homologada pela CP - Capitania dos Portos - com 
jurisdição sobre a ZP, para ser empregada no deslocamento e no transbordo do Prático para o embarque/desembarque na embarcação" (NORMAM 12, 2000).

Esta lancha é de uso exclusivo para a praticagem, salvo casos excepcionais em que é requisitada pela autoridade marítima, como por exemplo para fiscalização do tráfego aquaviário, socorro e salvamento. É dotada de equipamentos de comunicação, navegação e salvatagem.

Os tripulantes das lanchas de prático recebem treinamento para as fainas de embarque e desembarque dos Práticos, de forma a aprimorar seus condicionamentos nas eventuais situações de emergência e, na adoção de medidas preventivas de acidentes. (CONAPRA, 2012).

Faina de praticagem, conforme citado acima, é definida pela NORMAM 12, como sendo:

a) Para efeito destas Normas, é a atividade que envolve a realização de manobra(s) de praticagem e/ou navegação de praticagem em uma ZP.

b) A faina de praticagem é computada para efeito da manutenção da habilitação do Prático e do cumprimento do Programa de Qualificação de Praticante de Prático.

\subsection{O PRÁTICO}

Não há praticagem sem o objeto principal deste estudo, o prático. Este é definido pela NORMAM 12/2003, no capítulo I, art. 2: "Prático - aquaviário não-tripulante que presta serviços de praticagem embarcado". Tem a função indispensável de assessorar o comandante na navegação dentro das ZP's - Zonas de Praticagem - onde se exige maior conhecimento da área navegada, pois, muitas vezes existem bancos de areia, rochas e rochedos, marés e correntes marítimas ou outros fatores que podem vir a prejudicar a embarcação. O Conselho Nacional de Praticagem também o define:

Profissional especializado que possuindo grande experiência e conhecimentos técnicos de navegação e de condução e manobra de navios, bem como das particularidades locais, correntes e variações de marés, ventos reinantes e limitações dos pontos de acostagem e os perigos submersos ou não, assessora o Comandante na condução segura do navio em áreas de navegação restrita ou sensíveis para o meio ambiente. (CONAPRA, 2012)

Portanto, o comandante pode navegar durante dias e por diversos lugares diferentes, porém, a cada porto que chega, precisa da presença do prático a bordo para auxiliar nas operações de atracar ou desatracar o navio.

Para se tornar o objeto principal da praticagem, é necessário prestar concurso realizado pela Marinha do Brasil. Na verdade, o concurso se dá para Praticante de Prático. Após conseguir se classificar através do concurso, é preciso participar do Programa de Qualificação do Praticante de Prático, que tem duração mínima de 12 e máxima de 20 meses. Obtendo êxito nessa fase, por último, existe o exame de Habilitação para Prático. Depois de ter todas essas etapas concluídas com sucesso, o profissional está habilitado para exercer a profissão.

Apesar do concurso ser realizado pela Marinha, o praticante de prático e o prático não são funcionários públicos, nem militares. "O Processo Seletivo à Categoria de Praticante de Prático, portanto, não se destina ao provimento de cargo ou emprego público, não sendo, 
consequentemente, concurso público de que trata o Art. 37, II, da Constituição Federal" (Comando da Marinha, Edital, 2011).

Esses profissionais têm possibilidade de exercer suas atividades atuando de modo individual, reunidos em associações ou até mesmo contratados por empresas. "O serviço de praticagem será executado por práticos devidamente habilitados, individualmente, organizados em associações ou contratados por empresas" (Brasil, 1997).

Muito se comenta sobre a remuneração desses profissionais, apesar do processo se dar por meio concurso, não se tem um valor fixo de salário. O preço cobrado por cada manobra é baseado no tamanho e peso da embarcação fixado em tabela, no entanto, podendo ser negociado diretamente com o armador. $O$ custo pelas manobras, previsto tabela se diferencia a cada porto, pois cada um possui características diferentes, exigindo maior ou menor esforço no auxílio ao Comandante.

\subsubsection{Dos deveres do prático}

A NORMAM 12 estabelece os deveres do prático. Serão citados apenas os que fazem referência a este trabalho, quais sejam: Assessorar o Comandante da embarcação na condução da faina de praticagem, atendendo, com presteza e de forma eficiente, as exigências do serviço de praticagem; manter-se apto a prestar o serviço de praticagem em todos os tipos de embarcações e em toda a extensão da ZP; comunicar, com a maior brevidade possível, ao comandante da embarcação e à CP/DL/AG, a existência de condições desfavoráveis ou insatisfatórias para a realização da faina de praticagem e que impliquem risco à segurança da navegação; executar as atividades do Serviço de praticagem, mesmo quando em divergência com a empresa de navegação ou seu representante legal, devendo os questionamentos serem debatidos nos foros competentes, sem qualquer prejuízo para a continuidade do Serviço.

As divergências relativas a assuntos técnico-operacionais referentes à segurança do tráfego aquaviário, à salvaguarda da vida humana nas águas e à prevenção da poluição hídrica serão dirimidas pela Autoridade Marítima. Ao prático caberá ainda cumprir o número mínimo de fainas de praticagem estabelecido para manter-se habilitado e manter-se em disponibilidade na $Z P$, durante todo o período de escala, para atender a qualquer faina de praticagem. Em caso de necessidade de afastamento da ZP por motivo de força maior, o prático deverá ser substituído na Escala e o fato informado à $\mathrm{CP} / \mathrm{DL} / \mathrm{AG}$ na primeira oportunidade.

\subsection{DO TRIBUNAL MARÍTIMO}

O tribunal marítimo teve sua criação devido a um fator histórico ocorrido na Cidade do Rio de Janeiro em 1930. Um navio alemão de nome Baden foi metralhado ao cruzar a saída da barra da cidade por não obedecer a sinalização dada pela Fortaleza de Santa Cruz com a ordem de parar. $\mathrm{O}$ acontecido deixou mortos e feridos.

O caso foi julgado pelo tribunal marítimo alemão alertando as autoridades brasileiras para a necessidade de um Tribunal com essas competências na nossa nação. "Desse modo, sentimonos inferiorizados por não possuirmos uma Justiça Marítima. Tal fato, entre outros incidentes, veio influenciar a Subcomissão Parlamentar de Direito Marítimo, que elaborou um Anteprojeto 
prevendo a criação de tribunais marítimos administrativos no país", afirmou o ex-presidente do tribunal marítimo Mário Augusto de Camargo Ozório.

A Lei n. 2.180/54 regulamentou a criação do tribunal marítimo, e o define em seu Artigo $10:$

\begin{abstract}
O Tribunal Marítimo, com jurisdição em todo o território nacional, órgão, autônomo, auxiliar do Poder Judiciário, vinculado ao Ministério da Marinha no que se refere ao provimento de pessoal militar e de recursos orçamentários para pessoal e material destinados ao seu funcionamento, tem como atribuições julgar os acidentes e fatos da navegação marítima, fluvial e lacustre e as questões relacionadas com tal atividade, especificadas nesta Lei. (BRASIL, 1954).
\end{abstract}

Sua sede encontra-se no Rio de Janeiro, tem jurisdição para julgar os acidentes e fatos marítimos, lacustres e fluviais. "Portanto, é órgão do poder executivo, tendo sua autonomia limitada para julgar as causas previstas na Lei supracitada, sendo o único tribunal do gênero no Brasil." (PIMENTA, 2007, p. 92).

Vale ressaltar que a expressão "jurisdição", em sua conceituação básica, é a atividade restrita ao Estado que declara ou realiza o direito para o caso concreto. Portanto, é a atividade que pressupõe órgão jurisdicional jungido pelo Poder Judiciário, nos moldes do artigo 92 da Constituição Federal.

De acordo com o que foi visto, o TM não pertence ao Poder Judiciário, fazendo parte do Poder Executivo, não desempenhando a atividade jurisdicional no seu sentido estrito.

As decisões tomadas por este tribunal poderão ser reexaminadas posteriormente pelo Poder Judiciário. A própria lei que regula o Tribunal Marítimo adota o direito o reexame pela justiça comum no seu Art. 18: "As decisões do Tribunal Marítimo quanto à matéria técnica referente aos acidentes e fatos da navegação têm valor probatório e se presumem certas, sendo porém suscetíveis de reexame pelo Poder Judiciário".

Em relação às punições, quando necessárias, aos práticos, são realizadas, na maioria das vezes por este tribunal, através dos chamados procedimentos administrativos.

\title{
3.3 DO PROCEDIMENTO ADMINISTRATIVO
}

Os procedimentos para a investigação e, se for o caso, punição dos práticos está regido pela já mencionada Lei n. 2.180/54, esse processo se dá em várias fases. A primeira dela é o inquérito previsto no Art. 33: "Sempre que chegar ao conhecimento de uma capitania de portos qualquer acidente ou fato da navegação será instaurado inquérito".

Será responsável por esse inquérito a capitania na qual a jurisdição tiver ocorrido o fato ou acidente de navegação, abrindo essa investigação no prazo de cinco dias a partir da data que a CP tomou conhecimento do ocorrido. Caso isso não aconteça, será de competência do Comandante da Marinha ou do Tribunal Marítimo (provocado pela procuradoria) fazê-lo.

$\S 2$ ㅇ Se qualquer das capitanias a que se referem as alíneas a, b e c, do parágrafo precedente não abrir inquérito dentro de cinco dias contados daquele em que houver tomado conhecimento do acidente ou fato da navegação, a providência será determinada pelo Ministro da Marinha ou pelo Tribunal Marítimo, sendo a 
decisão dêste adotada mediante provocação da Procuradoria, dos interessados ou de qualquer dos juízes. (BRASIL, 1954)

Se a investigação apontar possíveis responsáveis, eles terão o prazo de dez dias para apresentar defesa prévia. Com a conclusão do inquérito, a Capitania dos Portos deverá encaminha-lo ao TM.

Em segundo tópico, acontece a Instauração do processo no Tribunal Marítimo.

O processo perante o TM tem início por iniciativa pública ou privada. Por iniciativa pública, ocorre por representação da Procuradoria ou por decisão do próprio Tribunal. Por iniciativa privada, tem o seu início por representação da parte interessada, nos moldes do parágrafo primeiro, do artigo 41, da 2.180/54. (PIMENTA, 2001, p. 96-97).

Com o recebimento da representação ou a negação do arquivamento do processo, o relator irá determinar a citação do possível responsável, segundo a legislação do Tribunal Marítimo, sob pena de nulidade caso não ocorra o cumprimento das formalidades ali expressas. Após esse processo é garantido o direito de defesa do acusado, tendo o prazo de quinze dias para apesentar sua defesa escrita, seguidos pelo momento de instrução e julgamento. Para ilustração, segue abaixo jurisprudência do Tribunal Marítimo com condenação do prático por erro de manobra, conforme o Anuário de Jurisprudência do Tribunal Marítimo, Volume XLIX, ano 1991 citado por Matusalém Gonçalves Pimenta (2007):

Processo no14.113/90. Relator: Juiz José do Nascimento Gonçalves. EMENTA: N/M VERBENA, de bandeira liberiana. Colisão com o cais durante manobra de atracação, auxiliado por dois rebocadores. Erro de manobra. Condenação. Autora: A Procuradoria. Representado: Luiz Felippe Vieira Pereira (prático). ACORDAM os juízes do Tribunal Marítimo, por unanimidade: a) quanto à natureza e extensão do acidente: colisão; b) quanto à causa determinante: falta de coordenação e planejamento; erro de manobra e c) decisão: julgar procedente a representação. Culpado o Prático Luiz Felippe Vieira Pereira, incurso no Art. 14, letra "a", da Lei 2.180/54 aplicando-lhe a pena de multa de CR\$ 45.000,00 (quarenta e cinco mil cruzeiros). Custas na forma da Lei. Na multa, vencido o juiz Luiz Carlos Salviano que aplicava a pena de CR\$ 500.000,00 (quinhentos mil cruzeiros. P.C.R. Rio de Janeiro, RJ, em 10 de dezembro de 1991 - EDSON FERRACCIÚ, Vice-almirante (RRm) Juiz-Presidente. - JOSÉ DO NASCIMENTO GOLÇALVES, Juiz-Relator.

O TM poderá adotar penalidades previstas na Lei $n$. 2.180/54, das quais interessa para este trabalho: repreensão, suspensão do pessoal marítimo, interdição para o exercício de determinada função, cancelamento da matrícula do profissional e a multa, como foi utilizada acima, podendo ser cumulativa ou não com qualquer outra sanção. "Assim, a responsabilidade administrativa do prático está jungida à Autoridade Marítima e ao Tribunal Marítimo, podendo o prático sofrer penalidades aplicadas por este ou por aquela Autoridade." (PIMENTA, 2007. p. 103). 


\title{
4 RESPONSABILIDADE CIVIL DO PRÁTICO
}

O prático sempre foi exonerado no que diz respeito a sua responsabilidade civil com base no entendimento da comunidade marítima internacional. Porém, existe um grupo minoritário, indo na visão contrária, grupo esse ocupado em sua maioria pelos armadores de navios. $\mathrm{O}$ fato ganhou repercussão maior no Brasil na medida em que começaram a surgir ações civis de indenização pelos danos causados pelos práticos no exercício de suas funções.

Os doutrinadores têm divergido bastante no que diz respeito a esse assunto. "Enquanto o prático estiver a bordo, ou de qualquer forma conduzindo a embarcação sob sua responsabilidade, presume-se responsável por qualquer acidente ou fato de navegação, respeitados os limites de suas atribuições" (GIBERTONI, 2005, p.139). Diferente de Gibertoni, Pimenta diz: “... por parte da comunidade marítima internacional, de que o dever de indenizar, por quaisquer danos causados por acidentes de navegação, compete aos armadores ou afretadores, visto que o risco de sinistro encontra-se incerto na aventura marítima" (2007, p.103). Tendo como ponto de partida tais entendimentos, é necessário, para um maior esclarecimento, compreender a relação entre o prático e o armador do navio.

Em apertada síntese podemos entender como armar o navio o ato de provê-lo de todos os meios necessários para uma expedição marítima.

\begin{abstract}
Objetivamente, por armação se entende a operação consistente em aprestar o navio para determinada expedição marítima; subjetivamente, em sentido que poderíamos dizer corporativo, armação significa a profissão do armador, a exploração comercial do navio. (MARTINS, 2005, p. 356 apud PIMENTA, 2007, p. 117).
\end{abstract}

No nosso ordenamento jurídico, o armador e o dono do navio possuem relações jurídicas distintas. O dono do navio poderá também ser o armador, conhecido como "armadorproprietário", porém isso não acontece necessariamente, podendo este alugar, arrendar, fretar a embarcação, bem como contratar um terceiro para o exercício desta tarefa.

Sobre a responsabilidade do armador, se tem como consolidação internacional que danos causados a terceiros são de responsabilidade do dono, armador ou afretador, ficando isto a mercê do contrato realizado entre eles. De acordo o a lei n. 9.537/97, artigo 20, III; "o armador está definido como pessoa física ou jurídica, que em seu nome e sob sua responsabilidade, apresta a embarcação com fins comerciais, pondo-a ou não a navegar por sua conta" (BRASIL, 1997). Em razão dos grandes ricos corridos na navegação, se tornou indispensável a aquisição de um seguro para a embarcação.

Para se protegerem desses riscos, os armadores buscaram a cobertura de seguros, através dos famosos "clubes de proteção" (P\&I - Protection and Indemnity), com a finalidade de fazer frente aos prejuízos causados por barataria do pessoal de bordo, incluindo o comandante, os demais tripulantes e o prático. (PIMENTA, 2007, p. 103).

Pelos grandes riscos corridos e a cobertura por várias modalidades de seguro, é possível enquadrar o armador na Teoria da Responsabilidade objetiva. "Haverá obrigação de reparar o dano, independentemente de culpa, nos casos especificados em lei, ou quando a atividade 
normalmente desenvolvida pelo autor do dano implicar, por sua natureza, riscos para os direitos de outrem". (Brasil. Lei no 10.406 de 10 de janeiro de 2002). Deixando assim, explícita a ideia de que em caso de acidentes, o alvo para ação indenizatória civil será o armador.

A doutrina Martins corrobora com o citado acima: "Os tribunais vêm consagrando a Teoria da Responsabilidade Objetiva ou do Risco Profissional do Armador, imputando-lhe responsabilidade independentemente de culpa, essencialmente no âmbito cível e administrativo" (MARTINS, 2005, p. 367 apud PIMENTA, 2007, p. 123).

No Brasil o serviço de praticagem é executado através de acordo de prestação de serviços entre as associações de praticagem e as empresas de navegação ou seus representantes legais. Porém, de acordo com alguns fatores que serão expostos a frente, não poderemos classificar esse acordo como um simples contrato. Uma das características da relação contratual é a liberdade de contratar, fato esse que não acontece de forma absoluta no serviço de praticagem, pois, ambos são obrigados a realizar o contrato. A praticagem, de acordo com a lei pátria, é uma atividade essencial ao interesse público, não havendo a possibilidade da não-utilização do serviço por parte dos armadores, muito menos podendo ser negada a prestação de serviço pelo prático. "O prático não pode recusar-se à prestação de serviço de praticagem sob pena de suspensão do certificado de habilitação ou, em caso de reincidência, cancelamento deste" (BRASIL, 1997). "Outra característica da relação contratual é a bilateralidade quanto à escolha de seu conteúdo, característica essa extremamente mitigada nos acordos de praticagem" (PIMENTA, 2007, p. 125).

Tal característica citada por Pimenta, não é encontrada nesse serviço, pois ele, obrigatoriamente, tem que ser realizado de acordo com a lei e regulamentos pertinentes. Para exemplificar, podemos citar o acordo realizado entre a praticagem do Rio de Janeiro e o Sindicato das Agências Marítimas do Estado do Rio de Janeiro, citado por Pimenta (2007, p. 125):

Cláusula 2o: o presente acordo está subordinado aos dispositivos legais e regulamentos que regem os serviços de praticagem, em especial à Lei no 9.537/97 (LESTA), ao Decreto no 2.596/98 (RLESTA), à NORMAM 12 - Norma da Autoridade Marítima para o Serviço de Praticagem - e às Normas e Procedimentos da Capitania dos Portos do Estado do Rio de Janeiro (NPCP).

Nesse cenário, precisa haver equilíbrio entre as partes nas relações contratuais, se isso não acontecer, poderá haver a rescisão contratual. A partir disso, passamos a analisar a posição do prático no navio. De acordo com o artigo 9o da LESTA: "Todas as pessoas a bordo estão sujeitas à autoridade do comandante" (BRASIL, 1997), assim, causando uma relação de hierarquia entre comandante e o prático.

Em suma, podemos evidenciar que um simples acordo contratual regendo a relação jurídica entre os armadores e o os práticos não é o suficiente, ou até mesmo correto.

Na medida em que não há liberdade de contratar, a escolha do conteúdo é fortemente mitigada pela legislação especial, e também não vigora o princípio do equilíbrio entre as partes, pois o serviço é executado sob a autoridade hierárquica do comandante. Assim sendo, essa relação jurídica [...] é híbrida, sendo contratual na sua formatação, mas, entretanto, na sua execução aproxima-se muito mais de uma relação de trabalho, na medida que é exercida sob subordinação. (PIMENTA, 2007, p. 126). 
Como já mencionado anteriormente, o prático presta serviço de assessoramento ao comandante, indicando a rota que o navio deve seguir, ficando por conta do comandante a direção do navio e as responsabilidades por acidentes originadas de erros técnicos da navegação. De acordo com a Norman 12, caso o comandante perceba que a assessoria do prático pode comprometer a segurança da embarcação, ele poderá dispensar os serviços do profissional.

Porém, segundo o entendimento de Matusalém Pimenta (2007), se o erro é cometido por especificidades locais, que deveriam ser do conhecimento do prático e não estão ao alcance do conhecimento do comandante, que cause por exemplo, o encalhe do navio, o prático deverá ser responsabilizado por seu erro. Pode-se entender através disso que, se o erro for de caráter genérico da navegação, podendo ser evitado pelos conhecimentos do comandante, este deverá ser o responsabilizado pelo ato, porém, se o erro se dá através de conhecimentos específicos da área de ação do prático, ele que deverá assumir a responsabilidade.

\begin{abstract}
Ademais, a presença do prático a bordo não desobriga o comandante e a equipe de passadiço (tripulação de serviço) de seus deveres e obrigações para com a segurança do navio, devendo as ações do prático ser monitoradas todo o tempo. Atualmente, a jurisprudência Cível e do Tribunal marítimo têm adotado a responsabilidade subjetiva, pessoal do comandante, fundada em culpa no sentido lato sensu (atos dolosos ou culposos). Destarte, o comandante não será responsabilizado pelos acidentes advindos de sugestão do prático, a menos que fique evidenciado que essas sugestões estavam evidentemente erradas e o comandante teria condições de perceber tal fato. (MARTINS, 2005, p. 447 apud PIMENTA, 2007, p. 131).
\end{abstract}

Caso seja constatado o erro do prático, ele estará sujeito a severas punições administrativas pelo Tribunal Marítimo. Todavia, isso não quer dizer que devido ao erro, o prático deverá sofrer ações civis indenizatórias por terceiros.

Pimenta (2007) especifica quatro razões para que o prático não tenha responsabilidade civil indenizatória por terceiros, dos quais corroboro com a opinião. São eles:

a) A responsabilidade objetiva do armador: Como já explicado anteriormente, pelo armador possuir a responsabilidade objetiva, conceito esse difundido internacionalmente e, por esta razão, possuir várias modalidades de seguro frente ao alto custo de qualquer acidente marítimo possa causar, o prático já estaria livre de tal responsabilidade, podendo ser acionado apenas em caso de Direito de Regresso.

b) Pela noção de preposição: “A responsabilidade objetiva do armador também é caracterizada pelo fato de o prático enquadrar-se na noção de preposição [...]" (PIMENTA, 2007, p. 139). Para entende essa noção de preposição, podemos citar Cavalieri Filho:

Preposto é aquele que presta serviço ou realiza alguma atividade por conta sob a direção de outrem, podendo essa atividade materializar-se numa função duradoura (permanente) ou num ato isolado (transitório) (...) De se ressaltar que a noção de preposição vem sendo ampliada pelos Tribunais, principalmente pelo Superior Tribunal de Justiça, de modo a permitir a responsabilização do dono do veículo que permitir seu uso por terceiros, seja a título de locação (súmula no 
492), seja a título de empréstimo, ainda que apenas para agradar um filho, um amigo ou conhecido. (CAVALIERI, 2004, p. 198 e 199 apud PIMENTA, 2007, p. 140).

Pimenta (2007) ressalta ainda a doutrina de Venosa para uma maior relação entre o armador e o prático:

Há, geralmente, uma dependência ou sujeição do preposto ao comitente, decorrente da autoridade deste, ou seja, o direito de dar ordens e instruções sobre o modo de cumprir as funções que são atribuídas ao preposto, assim como o direito de fiscalizar e até intervir no trabalho. (VENOSA, 2005, p. 88 apud PIMENTA, 2007, p. 140).

Essa dependência e sujeição citadas acima, se relacionam com o prático e o comandante, uma vez que todos a bordo estão sujeitos à autoridade deste e, o serviço daquele deverá ser monitorado pela autoridade máxima a bordo, podendo também intervir no seu trabalho.

a) Aumento dos custos portuário: Se os práticos fossem, por regra, responsabilizados civilmente por terceiros, os custos portuários se elevariam, pois, diante dos grandes valores que poderiam surgir das ações indenizatórias os práticos e as suas associações seriam forçados a buscar seguros adicionais, custos esses que seriam repassados para a tabela dos serviços de praticagem.

b) Suprema Corte Marítima Brasileira: Em 1991 foi emitida através do juiz do tribunal Dr. Luiz Carlos de Araújo Salviano a opinião de tal corte em artigo publicado na Revista Embarque do Prático:

Em parecer emitido pelo Egrégio Tribunal Marítimo, em 1991, aquela Colenda Corte de justiça Marítima já afirmava que o armador era civilmente responsável pela reparação de danos decorrentes de fatos e acidentes da navegação previstos em sua Lei Orgânica, ou seja, na Lei no 2.180, de 5 de fevereiro de 1954, provocados por erro de práticos no exercício de suas atividades laborativas a bordo. (SALVIANO, 2000, p. 11 apud PIMENTA, 2007 p. 144).

O juiz ainda enfatiza nesse mesmo texto o impacto psicológico que a responsabilização civil do prático poderia ocasionar. Segundo ele, a possibilidade de perdas patrimoniais, conquistadas com o seu trabalho, em razão dos altos valores de indenização causados por este tipo de ação, originaria uma grade pressão psicológica, gerando insegurança e intranquilidade, podendo tornar-se um fator natural para a ocorrência desses eventos danosos.

Além disso, por menor que seja um acidente ocorrido com a navegação, os valores para tal conserto são altíssimos, podendo muitas vezes até ultrapassar o valor de todos os bens que o prático possui.

Atualmente, os tribunais cíveis, em sua maioria, vêm compartilhando desta mesma visão, isentando o prático de qualquer responsabilidade civil. Segundo Gibertoni "O dia-a-dia tem consagrado a isenção total posto que, reparos de navios, após abalroamento, encalhe ou colisão, sempre são calculados e os montantes superiores a capacidade de pagamento de uma pessoa física ou empresa de praticagem" (2005, p. 139). 


\section{RESPONSABILIDADE CIVIL DO PRÁTICO NO DIREITO COMPARADO}

Como a nossa legislação não se manifesta claramente sobre o assunto, vamos buscar soluções possíveis através da comunidade marítima internacional por meio do Direito Comparado.

Segundo a doutrina, podemos entender como um estudo comparativo entre direitos de outros países. "O que a doutrina chama de 'direito comparado' é, na verdade, um estudo comparativo entre direitos, ou, com uma maior exatidão, um método de interpretação comparada" (SIQUEIRA, 2013). Muitas nações já optaram pela limitação da responsabilidade civil do prático e outras pela total não-responsabilização durante a execução do seu serviço, uma delas foi a Austrália.

Segundo Pimenta (2007), a lei marítima australiana previa uma limitação à responsabilidade civil do prático, porém por alguns entraves jurídicos, determinou através de uma emenda legislativa, pela não responsabilização em caso de acidentes durante o serviço de praticagem.

Marine Act, 1988. Art. 104 - Limited liability of pilots; A pilot is not liable in negligence in respect of the voyage on which the pilot is engaged for more than $\$ 200$ plus the amount of pilotage in respect of that voyage. (AUSTRÁLIA, 1988).

Lei marítima, 1988. Art. 104 - Responsabilidade Limitada dos Práticos - O prático não será responsabilizado por negligência durante a navegação sobre a zona de praticagem, em valores superiores a duzentos dólares, mais o valor cobrado por tal serviço. ${ }^{1}$

Já em 2006 a atualização da lei:

The Maritime Legislation Amendment Act, 2006. 410B (3) Civil liability in relation to if a pilot: (a) does an act, issues an instruction, or provides information or advice in or in relation to the pilotage of a ship; and (b) that act is done, that instruction is issued, or that information or advice is provided, in the course of the pilot's duty and in good faith; and (c) that act, instruction, information or advice affects the navigation of the ship so that loss or damage is caused to or by the ship; neither the pilot nor any pilotage provider responsible for the provision of the pilot's services is liable in civil proceedings for that loss or damage. (AUSTRÁLIA, 2006).

Emenda Legislativa à Lei Marítima Australiana, de 2006, Art. 101, subseção 410 (B), que prevê sobre a Responsabilidade Civil em relação ao prático quando este:

a) Age, emite uma instrução ou presta informação ou conselho no ou em relação ao serviço de praticagem;

b) Este ato é executado, esta instrução é emitida ou esta informação ou conselho são dados, durante a faina de praticagem e, o são de boa-fé;

c) Este ato, instrução, informação ou conselho compromete a navegação do navio de modo a causar perdas e danos no navio ou por ele; nem o prático, nem qualquer

1 Tradução livre 
outro responsável pelo fornecimento dos serviços de praticagem, deverão ser civilmente responsáveis por estas perdas e danos. ${ }^{2}$

É salutar citar os Estados Unidos também como exemplo. Por permitir a responsabilização dos práticos civilmente, o país adotou um sistema chamado "dual rate". Este sistema adotava dois valores para o serviço de praticagem; o primeiro, sem qualquer acréscimo, responsabilizava o armador por qualquer dano ocorrido durante a faina de praticagem, já o segundo, tinha um custo muito maior, pois os práticos assumiriam a responsabilidade civil, assim obrigavam estes profissionais a terem seguro e isso refletia diretamente no montante arcado pelos armadores.

Com isso, os donos dos navios optavam pelo menor preço, pois preferiam correr os riscos a pagar muito mais pelo mesmo serviço, deixando-o assim em desuso. Hoje, como ilustração, podemos apontar a legislação do Estado de Washington, no capítulo 88.16 da Lei da Praticagem citada por Pimenta (2007), como exemplo de responsabilidade limitada.

\begin{abstract}
A pilot licensed to act as such by the state of Washington, and any countywide port district located partly or entirely within the Grays Harbor pilotage district as defined by RCW 88.16.050(2) authorized to provide pilotage services with pilots employed by or under contract with the port district, shall not be liable for damages in excess of the amount of five thousand dollars for damages or loss occasioned by a pilot's or pilot trainee's errors, omissions, fault, or neglect in the performance of pilotage or pilot training services, except as may arise by reason of the willful misconduct or Gross negligence of the pilot. (WASHINGTON, 2005 apud PIMENTA, 2007, p.157).
\end{abstract}

Um prático licenciado para agir como tal no Estado de Washington e qualquer distrito portuário localizado parcial ou totalmente dentro da zona de praticagem Grays Harbor (...) não será responsabilizado civilmente por prejuízos que excedam o valor de cinco mil dólares por perdas e danos ocasionados por erros, omissões, falhas ou negligência na execução dos serviços de praticagem, exceto se houver a hipótese de dolo ou culpa grave do prático.

O fato ocorrido nos Estados Unidos ratifica a ideia erronia da responsabilização do prático civilmente, os próprios armadores rejeitaram essa opção pelo serviço ser mais caro. Na Europa, o Reino Unido também adotou a responsabilidade limitada aos práticos:

Pilotage Act 1987. Chapter 22 - Limitation of liability in respect of pilots; The liability of an authorised pilot for any loss or damage caused by any act or omission of his whilst acting as such a pilot shall not exceed $£ 1,000$ and the amount of the pilotage charges in respect of the voyage during which the liability arose. (REINO UNIDO, 1987).

Lei de Praticagem, 1987. Capítulo 22; A limitação da responsabilidade civil do prático - A responsabilidade civil de um prático autorizado durante sua manobra, não deverá exceder a importância de mil libras mais o valor cobrado pelo serviço de praticagem. ${ }^{3}$ Ainda na Europa, segundo Pimenta (2007), a França é exemplar no detalhamento da legislação que versa sobre o assunto deste trabalho.

\footnotetext{
2 Tradução livre

3 Tradução livre
} 
LOI No 69-8 DU 3 JANVIER 1969. Section 2 - Des pilotes. Article 18. Le pilote n'est pás responsible envers les tiers des dommages causés au cours des opérations de pilotage. Il doit contribuer à la réparation, dans ses rapports avec l'armateur navire piloté, dans la mesure où celui-ci ètablit que le dommage est dû à une faute du pilote. (...) Article 20 - Tout pilote doit founir um cautionnement. (FRANÇA, 1969 apud PIMENTA, 2007, p. 159).

Lei no 69-8, de 3 de janeiro de 1969. Seção 2 - Dos práticos. Artigo 18. O prático não é responsável perante terceiros pelos danos causados durante as fainas de praticagem. Ele deve contribuir para a reparação do dano com seus rendimentos perante o armador do navio praticado, na medida em que fica provado que o dano foi causado por um erro do prático. (...) Artigo 20 - Todo prático deve fornecer uma caução. (PIMENTA, 2007, p. 159).

Em 1986 foi aprovado um decreto que especificou onde essa caução deverá ser depositada.

ARRÊTÊ DU 3 SEPTEMBRE 1986. Article premier - La caissee de la fédération française de syndicats profissionnels de pilotes maritimes, domicilieé 74 , rue du Rocher 75008 Paris, est agréé comme caisse de garantie du cautionnement exgieé des pilotes maritimes par la loi. (FRANÇA, 1986 apud PIMENTA, 2007, p. 159).

“DECRETO DE 3 DE SETEMBRO DE 1986. Artigo primeiro - A caixa da federação francesa dos sindicatos profissionais dos práticos, sediada na rua Rocher, 74 - 75000 Paris, está aprovada como caixa de garantia da caução exigida aos práticos, por força de lei." (PIMENTA, 2007, p. 159)

Para completar o assunto, em 1999, surgiu o decreto que limitou o valor da garantia paga pelos práticos que, segundo Pimenta (2007) com a conversão na moeda atual, tem o valor de 10.000 euros.

ARRÊTÉ DU PREMIER JULLET 1999. Art. Premier - Le cautionnement des pilotes maritimes est fixe comme suit : - per les stations dont la liste est annexée au présent arrêté, le onant du cautionnement es de 65.595,70 F. (FRANÇA, 1999 apud PIMENTA, 2007, P. 159)

DECRETO DE PRIMEIRO DE JULHO DE 1999. Artigo primeiro - A caução dos práticos está fixada como segue - para as estações de praticagem cuja lista está anexada ao presente decreto, a quantia da caução é de 65.595,70 Francos. (PIMENTA, 2007, p. 159)

\section{PRÁTICA DO PORTO DE NATAL}

Em entrevista realizada com o presidente da Associação dos Práticos de Natal - Sebastião Rodrigues - pudemos conhecer mais a respeito desses profissionais e observar como funciona a responsabilidade civil dos práticos na prática na cidade do Natal. O porto de Natal, segundo Sr. Sebastião, é estreito, com pedras dos dois lados do canal, muito sujeito a ação dos ventos. Recebe navios com uma média de 180/200 metros de comprimento, principalmente os portacontainer, que chegam a suportar 400 containers de uma só vez. 
Atualmente, conta com seis práticos. O regime de trabalho se dá por meio de escalas, acordadas entre os próprios profissionais. Cada prático trabalha sete dias direto, ficando mais sete dias sobre aviso e uma semana de descanso.

Ao realizar o concurso, o candidato pode escolher as preferências de onde trabalhar. De acordo com a entrevista, é comum que coloquem Natal como uma das últimas opções, devido à baixa movimentação portuária, o que impede uma maior movimentação financeira, ficando o porto de Santos e Rio de Janeiro como os preferidos. Com isso, os práticos de hoje não têm o propósito de ficar definitivamente em Natal, e sim, realizar novo concurso para tentar mudar sua região de atuação. Essa situação pode ser ilustrada através de duas pessoas que passaram no concurso para trabalhar em Natal, porém, durante o exercício da profissão, fizeram o processo seletivo novamente e já estão sendo praticantes de prático em outra região.

Sr. Sebastião explica que a situação da movimentação do porto hoje em dia é muito fraca, piorando com a desativação do terminal da Petrobrás, que gerou o prejuízo de menos um navio por semana. Ele conta que até os barcos de pesca estão deixando de vir pra cá em razão de não ter combustível disponível no porto para o abastecimento, e o custo para o óleo diesel vir de caminhão ser muito alto. Basicamente, o movimento de navios no porto se dá através de quatro porta-containers por mês, porém, em época de chuva esse número cai cinquenta por cento.

Isso ocorre devido à exportação de melão, que é o principal produto de exportação do Estado, pois o sistema de produção se dá através de gotejamento. Quando chove há um desequilíbrio do sistema e a qualidade do produto diminui, caindo, consequentemente, a quantidade a ser exportada. Essa baixa movimentação afeta diretamente as condições de trabalho dos práticos, pois, o rendimento de sua profissão é por meio da movimentação dos navios e, com apenas dois navios por mês complica-se a situação dos seis práticos presentes no Porto.

Questionado se algum prático já ficou sem receber a remuneração durante algum mês, ele respondeu que, como é muito baixa a movimentação portuária, eles decidiram dividir todo o lucro gerado independente de qual prático tenha realizado a manobra. Após pagarem todas as despesas, eles dividem o restante igualmente pelos seis. Esse baixo movimento de navios, também prejudica diretamente a capacidade de manter a habilitação de prático, uma vez que eles necessitam de certa quantidade de manobras para mantê-la. Para resolver esse problema, a operação realizada em um navio é feita por dois práticos, um na entrada da embarcação na zona de praticagem e o outro na saída.

Outro assunto discutido foi a alta remuneração, que vem em destaque na mídia, que o serviço proporciona. Ele comentou que foi da maior infelicidade um jornal do Estado ter publicado de maneira genérica que os práticos tinham a remuneração de trezentos mil reais por mês. De acordo com o que foi apresentado, ele explicou que é impossível adequar isso à realidade do porto de Natal. Em suas palavras, ele fala que já tiveram meses deste ano de 2014 que a despesa da Associação foi maior que a receita, ficando ele e os outros profissionais no prejuízo. Tendo por base as explanações supra mencionadas pudemos perceber que o valor da praticagem difere de porto a porto, pois cada um possui peculiaridades diferentes do outro. Como exemplo, a manobra de entrada de um navio aqui em Natal tem em média três a quatro horas para ser realizada. Em algumas cidades do norte esse mesmo tipo de serviço pode durar de dois a três dias. Os valores também alteram-se conforme a tonelada e arqueação bruta do navio. 
Como vimos, durante as manobras o prático lida diretamente com o comandante. Perguntado se já houve algum conflito entre eles, Sr. Sebastião conta que nunca aconteceu com nenhum prático em Natal, porém, ele soube de casos, em outras zonas de praticagem, onde devido a conflitos entre esses dois profissionais, o comandante já se recusou a trabalhar com certo prático pedindo que ele saísse do navio e outro prático viesse substituí-lo.

Sobre as condições físicas do porto, o presidente da associação apenas reclamou dos rebocadores de navio que estão em péssimas condições de uso, segundo ele. Em relação a atualização dos seus conhecimentos sobre a zona de praticagem, ele informou que o último estudo realizado ocorreu quatro anos atrás, não tendo nenhum mais recente porque a Companhia Docas do Rio Grande do Norte (CODERN) afirma não ter recursos necessários para realização deste serviço. A praticagem potiguar nunca se envolveu em um acidente de grande magnitude. Contudo alguns pequenos acidentes já ocorreram. A exemplo, um navio encalhou quando se aproximava do porto de Natal (houve uma aproximação excessiva da área onde o navio precisa ficar fundeado para que o prático suba a bordo) e acabou furando o casco, gerando derramamento de óleo, o que levou à prisão do Capitão do Navio.

Neste caso, o óleo chegou à praia e teve repercussão entre banhistas, turistas e a rede hoteleira. Mas acidentes deste tipo não são uma grande exceção, explica ele, em razão do não controle total do navio, efeito da incidência de diversos fatores como a massa/peso do navio, corrente, a maré ou até mesmo a não resposta do navio como o esperado pelo prático ou capitão.

Em suma a responsabilidade do prático é muito grande, e este só é percebido quando ocorre algum evento negativo como algum tipo de acidente, afirma Sr. Sebastião. $O$ forte interesse particular no exercício da praticagem, como já mencionado anteriormente, também é um fator marcante na responsabilidade do prático, até mesmo pelo alto custo da carga, do navio, instalações portuárias e a responsabilidade com meio o ambiente.

Atualmente, como já observado, os acidentes marinhos têm sido julgados pelo Tribunal Marítimo. A exemplo no porto de Natal, há certo tempo, um navio estrangeiro estava atracando e uma parte dele posterior (bulbo do navio) colidiu com a defensa do porto, o que, apesar da insignificância do dano causado, gerou grande transtorno, até mesmo por envolver muitos interesses. Isto é, apesar da tentativa de resolver a situação de forma amigável, a pequena colisão gerou uma demanda judicial de $\mathrm{R} \$ 113.000,00$ que envolvia a CODERN demandando contra o navio estrangeiro/armador (inclusive pedindo seu arresto à Marinha) e, solidariamente contra o prático no Tribunal Marítimo. Neste caso, o prático foi absolvido do processo.

\section{CONSIDERAÇÕES FINAIS}

Este trabalho teve como aspecto principal estudado a Responsabilidade Civil do Prático. Para que a análise dessa responsabilidade ocorresse foi necessário realizar estudos sobre a Responsabilidade Civil e algumas de suas vertentes, a praticagem e todos os fatores envolvidos neste serviço, analisar a Responsabilidade civil do prático frente à legislação e a doutrina brasileira, buscar entendimento através da Comunidade Marítima Internacional por meio do Direito Comparado, além de fazer um diagnóstico sobre o tema no Porto de Natal. 
Por ser uma atividade de alto risco e, de acordo com o artigo 927 do Código Civil, fica clara a responsabilidade objetiva do armador, que por sua vez, se apoia em empresas seguradoras ou em clubes P\&I (protection and indemnity), que são associações de seguro mútuo que fornecem cobertura para os seus membros.

Os Clubes P\&I não aceitam, como membros, navios que não sejam classificados por uma Sociedade Classificadora reconhecida. De qualquer forma, é importante que fique claro, que mesmo possuindo a responsabilidade objetiva, o armador teria o direito de abrir uma ação contra o prático através do Direito de Regresso, se compreendesse que a conduta do mesmo contribuiu para o acidente. Porém, em face do Direito de Regresso precisa-se observar que os valores eventuais de uma condenação seriam altíssimos e dificilmente os práticos conseguiriam se sustentar se tivessem de arcar com tais prejuízos, pois qualquer reparo nas embarcações é extremamente caro. Por isso, é mais sensato que a embarcação tenha seguro ou faça parte de um clube $P \& I$.

Caso o prático fosse responsável civilmente, ele e as associações seriam obrigadas a também terem seguros para este tipo de caso, gerando o aumento nas taxas portuárias, tendo influência direta nos processos de importação e exportação. Tal modalidade, ou seja, uma maior responsabilização do prático, pôde ser analisada através do Direito Comparado, posto que os Estados Unidos adotaram esse sistema que acabou se desfazendo frente aos próprios armadores que optavam pelo serviço sem a responsabilização do prático, por uma questão de economia. Além disso, existe o fator psicológico. Trabalhar com o medo constante de que qualquer pequeno deslize possa comprometer todos os seus bens, conquistados através de anos de profissão, não ajudaria o profissional a entregar o melhor de si durante as manobras.

Então, pode-se concluir que a legislação brasileira já deveria ter um posicionamento direto sobre o assunto, frente que esse serviço é de interesse público, a quantia financeira envolvida nos acidentes é alta e até mesmo para que os principais profissionais da praticagem possam ter um posicionamento correto para esse tipo de situação.

Acredito que a Responsabilidade Civil do prático deverá seguir apenas pela jurisdição do Tribunal marítimo, sofrendo em caso de acidentes apenas punições administrativas frente a todos os aspectos demonstrados anteriormente, caso os processos passem a ser julgados nos tribunais comuns, deverá ser adotado o valor limite da responsabilidade, seguindo o modelo da Comunidade Marítima Internacional.

No início do trabalho, achávamos que conseguiríamos documentos a partir da justiça brasileira comum, porém, nos deparamos com a escassez de processos que versam sobre o tema desta monografia. Os processos decorrentes de responsabilização civil dos práticos, em sua grande parte, ficam no Tribunal Marítimo, fator este nos faz deduzir que este Tribunal consegue dirimir de forma eficiente os problemas que têm surgido neste âmbito.

Para exemplificar, podemos utilizar o caso de responsabilização civil do prático ocorrido no Porto de Natal, cujo processo foi desenvolvido e decidido pelo Tribunal Marítimo e, apesar de ter a opção de ser reexaminado pela justiça comum, foi considerado uma decisão definitiva.

As limitações do trabalho se deram através das fontes, por ser um assunto novo, em ascensão, as fontes ainda são muito escassas, sendo encontrado apenas um livro que trata diretamente sobre a Responsabilidade Civil do Prático. Ao tentar adentrar sobre tópicos mais 
específicos para o comércio exterior e marítimo, tivemos muita dificuldade em achar material necessário para desenvolver tópicos sobre isto, tendo que buscar a partir de pesquisas de campo, que, diante da riqueza de assuntos relacionados à praticagem percebidos, instigam a continuar pesquisando e estudando, o que não poderia ser concretizado completamente neste momento em razão do pouco tempo estabelecido para o desenvolvimento deste trabalho.

\section{REFERÊNCIAS}

1. AUSTRÁLIA. Emenda à legislação marítima (2006). Lei para alterar a legislação marítima e fins relacionados. № 24 de 2006. Disponível em:< http://www.comlaw.gov.au/Details/ C2006A00024>. Acesso em 19 ago. 2014.

2. AUSTRÁLIA. MARINE ACT n. 52 de 1988. Versão incorporando modificações, de 1 de julho de 2010. Versão n. 078. Disponível em: <http://www.legislation.vic.gov.au/Domino/Web_ Notes/LDMS/LTObject_Store/LTObjSt3.nsf/DDE300B846EED9C7CA257616000A3571/A09CA 8D353F0FE8FCA257761002831A8/\$FILE/88-52a078.pdf>. Acesso em: 18 ago. 2014.

3. BRASIL. Decreto de 12 de Junho de 1808. Cria o cargo de Piloto Prático no Rio de Janeiro e dá-Ihe regimento. Legislação Informatizada. Diário [da] República do Brasil, Rio de Janeiro, RJ, 12 de jun. 1808. Disponível em: <http://www2.camara.leg.br/legin/fed/decret _sn/anterioresa1824/decreto-40182-12-junho-1808-572165-publicacaooriginal-95281pe.html>. Acesso em: 17 ago. 2014.

4. BRASIL. Lei n. 10.406, de 10 de janeiro de 2002. Institui o Código Civil. Diário [da] República do Brasil. Poder executivo, Brasília, DF, 10 de jan. 2002. Disponível em: <http://www.planalto.gov.br/ccivil_03/leis/2002/l10406compilada.htm>. Acesso em: 17 ago. 2014.

5. BRASIL. Lei n. 2.180, de 5 de fevereiro de 1954. Dispõe sobre o Tribunal Marítimo. Diário [da] República do Brasil. Poder Executivo, Brasília, DF, 5 de fev. de 1954. Disponível em: <http://www.planalto.gov.br/ccivil_03/leis/L2180compilado.htm>. Acesso em: 18 ago. 2014.

6. BRASIL. Lei n. 5.056, de 29 de junho 1966. Modifica dispositivos da Lei no 2.180, de 5 de fevereiro de 1954, alterada pela de no 3.543, de 11 de fevereiro de 1959, que dispõe sobre o Tribunal Marítimo, e dá outras providências. Diário [da] República do Brasil. Poder Executivo, Brasília, DF, 29 de jun. de 1966. Disponível em: <http://www.planalto. gov.br/ccivil_03/leis/1950-1969/L5056.htm\#art1>. Acesso em: 10 de ago.2014.

7. BRASIL. Lei n. 9537/97, de 11 de dezembro de 1997. Dispõe sobre a segurança do tráfego aquaviário em águas sob jurisdição nacional e dá outras providências. Diário [da] República do Brasil. Poder Executivo, Brasília, DF, 11 de dez. de 1997. Disponível em: <http://www.planalto.gov.br/ccivil_03/leis/19537.htm>. Acesso em: 10 ago. 2014.

8. CONSELHO NACIONAL PRATICAGEM. Estação de praticagem - Atalaia. Rio de Janeiro. Disponível em: <http://www.conapra.org.br/?page_id=2315>. Acesso em: 18 ago. 2014.

9. DIRETORIA DE PORTOS E COSTAS. Normam 12: Serviço de Praticagem. Disponível em: <https://www.dpc.mar.mil.br/normam/N_12/N_12.htm>. Acesso: 15 jul. 2014. Acesso em: 10 de ago. 2014.

10. FILHO, Sergio Cavalieri. Programa de Responsabilidade Civil. 6o Ed. São Paulo: Malheiros Editores, 2005. 
11. GIBERTONI, Carla Adriana Comitre. Teoria e Prática do Direito Marítimo. 2o Ed. Rio de Janeiro: Renovar, 2005.

12. LOPES, Simone Dalila Nacif. A Visão do Desembargador Sergio Cavalieri Filho Sobre a Responsabilidade Civil nos 10 Anos do Código Civil na Construção da Doutrina e Jurisprudência. Rio de Janeiro, RJ: Escola da Magistratura do Estado do Rio de Janeiro, 2013. Disponível em: <http://www.emerj.tjrj.jus.br/serieaperfeicoamentodemagistrados/paginas/ series/13/volumell/10anoscodigocivil_vollI_222.pdf>. Acesso em: 13 de Ago. 2014.

13. MARINHA DO BRASIL. Normam-12/DPC 1ạ revisão: Normas da autoridade marítima para o serviço de praticagem. 2011. Disponível em: <https://www.dpc.mar.mil.br/normam/ N_12/normam12.pdf>. Acesso em 18 ago. 2014.

14. OZÓRIO, Mário Augusto de Camargo. O tribunal marítimo. Brasil. Disponível em: <http://www.egov.ufsc.br/portal/sites/default/files/anexos/21844-21845-1-PB.htm>. Acesso em: 13 de Ago. 2014.

15. PIMENTA, Matusalém Gonçalves. Responsabilidade Civil do Prático. Rio de Janeiro: Lumen Juris, 2007

16. PORTOS DO BRASIL. NORMAM-12 - anexo 4-A - Relação das Zonas de Praticagem. Disponível em: < http://www.portosdobrasil.gov.br/assuntos-1/gestao/praticagem/ arquivos/normam-12-anexo-4-a-relacao-das-zonas-de-praticagem.pdf>. Acesso em: 08 ago. 2014

17. PULA, Carolina Martinez. Do serviço de praticagem no Brasil. Jus Navigandi. Disponível em: <http://jus.com.br/revista/texto/17314>. Acesso em: 7 abr. 2013.

18. REINO UNIDO. Lei de Pilotagem 1987, de 15 de Maio de 1987. Lei para novas disposições em matéria de pilotagem. Disponível em: <http://www.legislation.gov.uk/ukpga/1987/21/ enacted>. Acesso em: 19 ago. 2014.

19. SIQUEIRA, Julio Pinheiro Faro Homem de. Natureza do Direito Comparado. Jus Navigandi, Teresina. fev. 2013. Disponível em: <http://jus.com.br/artigos/23674>. Acesso em: 08 ago. 2014.

20. TRIBUNAL MARÍTIMO. Incidente Com o Navio BADEN. Rio de Janeiro. Disponível em: < https://www.mar.mil.br/tm/historia.html>. Acesso em: 11 de Ago. 2013. 